cost sharing. Groups of students pay different levels of fees: lower fees for domestic undergraduates and higher fees for graduate students, international students, and in some instances adult learners.

MODEL FOUR: EXPANSION OF A PRIVATE SECTOR OF INSTITUTIONS.

This model of growth expands enrollments in private institutions to take up the slack created from restrictions in the size and growth of the public sector of tertiary education. This has occurred in a number of countries around the world either as a matter of deliberate government strategies or simply as an industry developing in response to unmet demand. In the Middle East and some countries in Asia, the number of private-sector institutions and students has grown particularly in vocational programs, although private universities have been the primary source of growth in some countries such as Japan and Korea. Poland is an example of an eastern European country that has become a mass higher education system largely through the growth of a private sector.

In some countries, the private institutions are for-profit while in others their organization is typically not-for-profit, with surpluses reinvested in the institution. What is common is that most enrollment growth occurs in the private sector while the number of students enrolling in public-sector institutions remains stable or grows very slowly as additional public funds are not made available. One way to encourage more enrollments in the private sector is to make students enrolling in these institutions eligible for the full range of student grants and loans. Another way to encourage private-sector growth is for governments to facilitate the approval of programs that meet minimal quality standards.

The four models of growth described above demonstrate that there are different routes for countries to achieve the goal of mass or universal tertiary education.

\section{Universities and Development: Goals of Success}

\section{Mohamed H. A. Hassan}

Mohamed H. A. Hassan is executive director of the Academy of Sciences for the Developing World (TWAS) in Trieste, Italy. E-mail: mhassan@twas.org. For additional information about TWAS, see www.twas.org.

Tn the I970s, universities in many developing countries 1 enjoyed strong support from their governments. Staffed by a youthful and well-trained faculty, equipped with adequate classrooms and laboratories, and spurred by the excitement and sense of purpose associated with new enterprises, institutions of higher education across the developing world seemed poised to gain additional strength in the future. For example, the University of Khartoum in Sudan, where I taught and served as dean of the school of mathematics for more than a decade, was one of the best universities not only in Africa but also throughout the developing world.

Throughout the late 1980 s and into the early 1990s, governments in many developing countries substantially reduced their investment in higher education.

So what happened? How did such promising circumstances turn into such a dismal situation in the late i980s and I990s? How did universities, especially universities in the world's poorest countries, become hollow, largely destitute institutions where little learning and even less research took place?

Part of the answer lies in forces well beyond the influence of scientists and scientific communities in developing countries. Political instability often accompanied by deadly violence; declining investments in higher education by both governments and international lending agencies; the rise of HIV/AIDS and other public health issues; and many other critical concerns, which demanded immediate responses, distracted attention from higher education and, more specifically, adversely impacted investments in science and technology in the developing world.

At the same time, aid agencies increasingly concluded that developing nations should focus on getting their economic house in order, usually by reducing governmental expenditures to curb public debt. They also came to believe that scientific research was a luxury that developing nations could not afford in light of the critical social and economic issues that they faced. The science and technology that developing countries needed, aid agencies reasoned, could be acquired from others.

As a result, throughout the late I980s and into the early I990s, governments in many developing countries substantially reduced their investment in higher education. Aid agencies, meanwhile, devalued the importance of building indigenous capacity in science and technology in the developing world.

The irony of this strategy was this: The critical issues that developing countries faced-whether a desire to reduce hunger and malnutrition, provide greater access to safe drinking water, curb disease and improve public health, or construct reliable energy systems-all necessitated the widespread applications of science and technology. Indeed, such efforts required not just any science and technology but appropriate 
homegrown science and technology that could effectively address critical indigenous problems.

Why, then, were universities not turned to as ideal places to study, research, and demonstrate science-based solutions to critical problems? Universities and professors in developing countries bear part of the responsibility for their marginalization. Having trained in universities in the developed world; having pursued dissertation topics of interest to the developed world; having forged joint research projects with colleagues in the developed world; and having defined a successful career by standards set by their counterparts in the developed world, scientists in the developing world-more often than not-found themselves disengaged from their societies.

After more than two decades spent largely exiled in developed countries or as castaways in their own nations, scientists in the developing world are now being welcomed back into their societies. This time, however, governments are insisting that investments in science and technology provide a payoff in terms of improvements in economic and social well-being. And this time, scientists are increasingly recognizing that they need to be responsive to their societies' concerns if the funding is to continue.

This rapprochement between science and society in the developing world has not been easy. Yet many signposts along the way have signaled the advances. These signposts include, for example, Brazil, China, and India's success in promoting science-based development; the growing maturity of university systems in these and other countries that has led institutions of higher education to embrace long-term responsibilities for education, research, and community service; and expanding efforts at South-South cooperation marked not only by exchange programs such as the South-South fellowship program of the Academy of Sciences for the Developing World for postgraduate and postdoctoral research, which provides some 250 fellowships a year, but the China-Brazil Earth Resources Satellite program, begun in 1998 , which has led to the launch of two Earth-imaging satellites, with two more launches planned by 2008. Indeed signposts, both large and small, abound, creating a sense of positive direction and optimism for the future of higher education in the developing world that is unprecedented.

Despite the recent progress, we must examine and evaluate on an ongoing basis what individual scientists and scientific institutions are contributing to society-in terms of improved nutrition, better health, more reliable energy supplies, enhanced communications, a cleaner environment and, perhaps most importantly, overall efforts to break the cycle of extreme poverty that has afflicted too many places in the developing world for decades.

Nevertheless, the key to success, especially for university departments and faculties of science lies in excellence. That's because science without excellence is not science. But success, as I have argued here, also lies in relevance. That's because without responding to the needs of society, university science departments will find it difficult to sustain society's support. Moreover, without educating and training students in ways that make them employable within their own countries, young scientists and technologists will not stay home once they graduate.

As recent history in the developing world shows, successful institutions of higher education without societal purpose will not be successful for long.

This article is reprinted, with permission, from IAU Horizons I2 (34), 2006. (C) International Association of Universities.

\section{Exam Trends and Global Talent Flows}

\section{Johnette Peyton and Veronica A. Garcia}

Johnette Peyton is a manager of applied research at the Graduate Management Admission Council@. Address: 1600 Tysons Boulevard, Suite 1400, McLean, VA 22102, USA. E-mail: jpeyton@gmac.com. Veronica A. Garcia is research writer/editor at the Graduate Management Admission Council@. E-mail:vgarcia@gmac.com.

Tn a recent issue of the Harvard Business Review, Richard Florida identified students as the leading indicator of global talent flow, stating that countries and regions that attract students have an advantage on retaining them and attracting additional pools of talent. If Florida's statement holds true, then new data from the Graduate Management Admission Council (GMAC) appear to demonstrate evidence of this new competitive landscape.

GMAC, a global not-for-profit education organization of leading graduate business schools and owner of the Graduate Management Admission Test (GMAT), publishes Geographic Trend Reports identifying migratory trends among GMAT examinees. Findings are based on voluntary responses to the GMAT background information questionnaire along with score report and registration information in a given testing year. The most recent report data include $2 \mathrm{I} 2,532$ examinee records in 200I and 200,503 in 2005. Approximately twothirds had US addresses at the time of registration in both years.

Test report submissions are used to gauge interest in studying in a particular region, as GMAT scores often accompany applications to graduate business programs. GMAC findings suggest geographic trends for examinees shifted drastically in some regions from 200I to 2005. Data from both years identify a strong preference for US programs overall with a slight decline from $200 \mathrm{I}$ to 2005 , as well as increasing interest in programs located in England, France, India, and Greece. 